\title{
O ENSINO DE ENZIMAS: UMA ABORDAGEM EXPERIMENTAL DE BAIXO CUSTO
}

\author{
William de Azevedo Pinheiro \& Wendel Mattos Pompilho \\ Universidade Estadual do Norte Fluminense - Darcy Ribeiro, Pólo CEDERJ, Itaperuna - RJ.
}

\section{Resumo:}

Este trabalho descreve uma atividade prática de Bioquímica, a qual expõe alternativas didáticas que visam facilitar processo ensino/aprendizado dos conceitos associados ao tema Enzimas. O estudo foi realizado em escolas de Ensino Médio da rede pública Estadual na região Noroeste Fluminense do Estado do Rio de Janeiro. $O$ trabalho consiste no desenvolvimento de uma atividade prática, sobre Enzimas, utilizando materiais alternativos e/ou de baixo custo. O trabalho objetiva, ainda, ser um agente de incentivo ao trabalho em equipes interdisciplinares dentro de uma visão holística multidisciplinar da construção do conhecimento, possível de ser explorada nas Ciências Biológicas e Exatas.

Palvras-chave: Enzimas, materiais alternativos, atividade prática, prática pedagógica.

\begin{abstract}
:
This paper describes a practical activity of Biochemistry, which proposes pedagogical and didactic alternatives designed to facilitate the teaching/learning concepts related to the theme regarding Enzymes. The study was conducted at public Senior High schools from the Northwestern Fluminense region of the State of Rio de Janeiro. The work consists in developing a practical activity on Enzymes, using alternative materials and/or low cost ones. In addition, the study aims at being an agent which may stimulate to work by means of dealing with interdisciplinary teams within a holistic multi-disciplinary construction of knowledge which can be exploited in the Biological Sciences and Exact Sciences.
\end{abstract}

Keywords: Enzymes, alternative materials, classroom practice, pedagogical practice. 


\section{INTRODUÇÃO}

O ensino de Ciências Biológicas tem obedecido a uma formulação puramente tradicional, ou seja, com uma base teórica, valendo-se de aulas expositivas com recursos limitados. Além disso, fenômenos que regem os processos biológicos são ensinados sem vínculos com a realidade dos alunos. Desta forma, o conteúdo referente à Biologia é visto pelos estudantes como abstrato, fictício, sem envolvimento com o seu cotidiano e pouca aplicabilidade [1].

Neste contexto, a Biologia que deveria ser uma disciplina empolgante e dinâmica, transformou-se meramente em um amontoado de classificações, estruturas, processos fisiológicos etc., desta forma, desviando o interesse dos alunos devido a um aprendizado maçante e monótono, levando-os a memorizar os temas da disciplina, objetivando as avaliações. Depois de avaliado o conhecimento é descartado, constituindo, assim, uma aprendizagem mecânica em detrimento de uma aprendizagem significativa [2].

Atualmente, conectar o conhecimento ensinado em sala de aula com o cotidiano dos alunos, e realidade das escolas públicas, é o grande desafio enfrentado pelos professores de Ciências e Biologia. Nesse contexto, a realização de atividades práticas é um mecanismo frequentemente utilizado para fazer esta ponte. Ao realizar uma atividade experimental, o aluno observa, compara, analisa, sintetiza e vivencia o método científico, desenvolvendo, por conseguinte, o raciocínio, a capacidade investigativa, e capacidade de formular conceitos [3].

A Lei de Diretrizes e Bases da Educação, de 1996, diz na seção IV, que se refere ao ensino médio, artigo 35, inciso IV, que deverá ser feito o relacionamento da teoria com a prática para toda disciplina. Neste sentido, é de suma importância que o professor saiba preparar e dirigir atividades práticas, trabalhando coletivamente em todo processo ensino/aprendizagem [4].

Com a premissa da falta de laboratórios, reagentes, materiais diversos, e equipamentos, na maioria das escolas públicas, muitos professores não utilizam atividades práticas como ferramenta de ensino. Porém, é possível ministrar um bom ensino de Ciências usando a criatividade para adaptar os materiais necessários às práticas [5].

No Ensino Médio, os temas associados à Bioquímica são abordados ao estudar a química da célula [6]. Geralmente, nas escolas públicas, estas informações são passadas aos estudantes de forma puramente teórica. De fato, uma abordagem de caráter apenas teórico pode ocasionar desinteresse e apatia ao longo do processo de formação destes alunos. Diante dessa possibilidade, fica a cargo do professor lançar mão da criatividade e propor a realização de atividades experimentais que permitam a participação ativa do aluno. Neste contexto, as salas de aula podem ser transformadas em laboratórios, os reagentes podem ser adquiridos em farmácias ou supermercados e os equipamentos produzidos, a partir de material de refugo [7- 10].

Por conseguinte, na trilha de tais pressupostos, este trabalho mostra como ensinar conceitos de enzima com base em uma atividade prática, a qual utiliza materiais de baixo custo e apresenta uma metodologia simples e interdisciplinar.

\section{MATERIAIS E MÉTODOS}

\section{A Área de Estudo}

Escolas públicas estaduais da Região Norte Fluminense do Estado do Rio de Janeiro foram selecionadas para realização deste trabalho (Tabela 1). A proposta foi aplicada junto aos alunos do $3^{\circ}$ ano do Ensino Médio. 


\begin{tabular}{|c|c|c|}
\hline Tabela 1: Relaçăo das escolas e número de alunos que participaram da pesquisa. \\
\hline Nome da Escola & Município (Distrito) & Número de Alunos \\
\hline Ary Parreiras & Laje do Muriaé & 25 \\
\hline Francisco Portella & Natividade & 25 \\
\hline 10 de Maio & Itaperuna & 87 \\
\hline Ciep 286 Lina Bo Bardi & Itaperuna & 92 \\
\hline José Garcia de Freitas & Itaperuna (Retiro do Muriaé) & 37 \\
\hline Almirante Baräo de Teffé & Pádua & 37 \\
\hline Temístocles de Almeida & Pádua (Monte Alegre) & $\mathbf{2 7 2}$ \\
\hline
\end{tabular}

\section{O Material Alternativo}

O alto custo das vidrarias, equipamentos, e reagentes para uso em laboratórios cria a necessidade da adaptação de materiais de baixo custo, em substituição aos materiais típicos de laboratório (Figura 1).

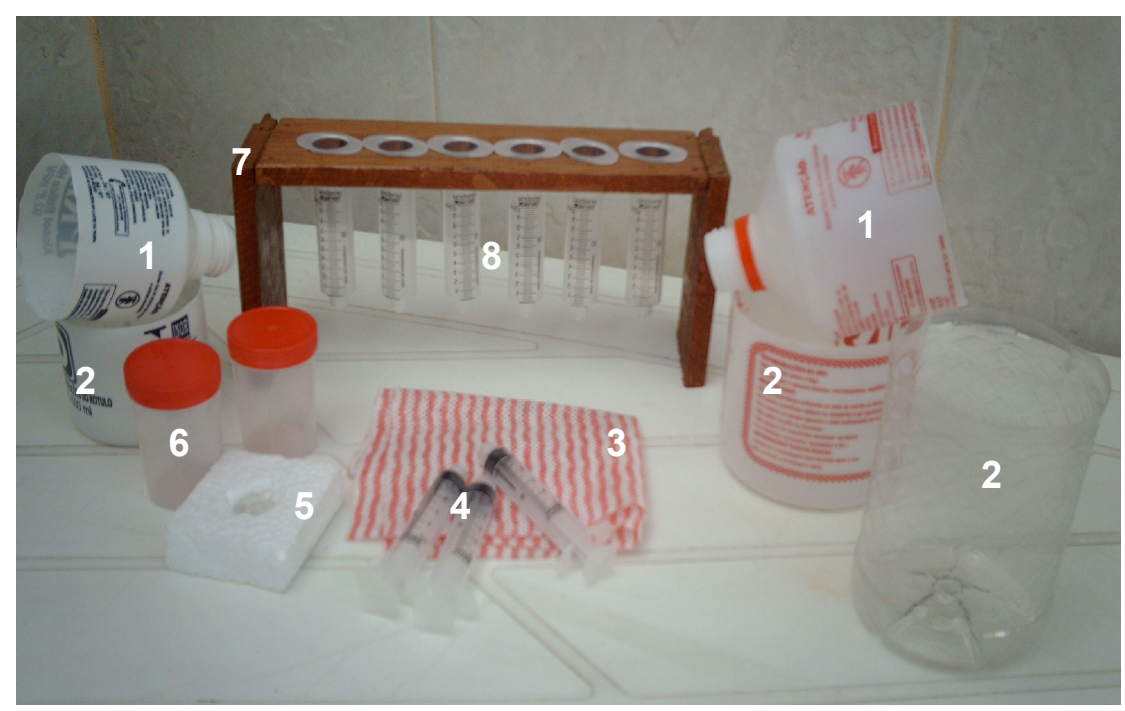

Figura 1: Material Alternativo. (1) Gargalo de garrafas com tamanhos variados; (2) Base de garrafas com tamanhos variados; (3) Pano tipo "perfex"; (4) Seringas de $5 \mathrm{~mL}$; (5) Placa de isopor; (6) Pote coletor; (7) Estante para tubos; (8) Seringas de $10 \mathrm{~mL}$.

\section{Trabalhando com os Alunos}

Uma sondagem por meio de questionário estruturado foi realizada com os alunos, a fim de verificar o nível de conhecimento sobre o tema enzimas (Anexo A).

Para iniciar a atividade prática, um texto base foi discutido com os alunos. $O$ assunto abordado no texto é a enzima catalase (Anexo B).

Após a discussão do texto base, as turmas foram dividias em grupos de 6 alunos cada; o material aplicado na prática (demonstrado na Figura 1, acima) e o protocolo experimental (conforme consta no Anexo C) foram distribuídos aos grupos. Na própria sala de aula, cada grupo reuniu-se em torno de duas mesas, usadas como bancada na execução dos experimentos. Os alunos foram orientados a participarem ativamente no desenvolvimento da atividade prática, cooperando entre eles durante realização dos experimentos.

O primeiro experimento realizado foi sobre o efeito da concentração de água oxigenada. A catalase de batata foi extraída através da simples trituração de pedaços de batata em água. Depois de coado, o extrato foi adicionado em tubos, em seguida a 
água oxigenada. O tempo de reação foi cronometrado e valores anotados na tabela encontrada no protocolo.

Neste experimento, foram ressaltados, para os alunos, os conceitos de enzima, substrato e produto, bem como a importância das enzimas para os seres vivos. De forma multidisciplinar, os alunos trabalharam a construção e a interpretação de gráficos (Anexo D).

No segundo experimento, foi discutido o efeito da temperatura sobre a atividade enzimática. Para isso, o extrato de batata foi adicionado aos tubos conforme orientação no protocolo e acomodado em temperaturas diferentes (ambiente fervura e congelamento). Após os tempos determinados para a acomodação dos tubos contendo o extrato, o substrato foi adicionado e anotou-se o que foi observado. Nesta atividade, foram discutidos com os alunos os efeitos da temperatura na atividade das enzimas (Anexo D).

Foi realizada, ainda, uma prática elucidando o efeito da variação do pH sobre a atividade enzimática. Para tanto, em um tubo, adicionou-se o extrato de batata e, em outro, vinagre acrescido de extrato de batata, aguardando o tempo como descrito no protocolo. Após a adição do substrato, os alunos verificaram se houve reação ou não, anotando os resultados na tabela do protocolo. Nesse experimento, a discussão ocorreu em torno do motivo pelo qual não houve reação no tubo que contém extrato mais vinagre (Anexo D).

Ao término da atividade prática, os alunos fizeram uma avaliação por meio de questionário estruturado (Anexo $\mathrm{E}$ ).

\section{RESULTADOS E DISCUSSÃO}

O ensino público, na região Noroeste do Estado do Rio de Janeiro, enfrenta uma série de problemas, dentre os quais é possível destacar: professores com sobrecarga de trabalho, baixos salários, poucos recursos didáticos para o ensino de ciências (laboratórios, microscópios, vidrarias etc.), curtos períodos de tempo das aulas, entre outros problemas que contribuem para que o ensino permaneça de forma tradicional. De fato, observa-se nas escolas que receberam este trabalho (Tabela 1 ) as condições tradicionais de ensino e os problemas citados anteriormente, porém são notórios o interesse e a motivação dos alunos ao participarem das atividades experimentais.

É importante destacar que as aulas práticas funcionam como meio de comunicação entre professor e alunos, bem como de construção e expressão de conceitos. Assim, a atividade prática torna a apreensão do conhecimento mais agradável e interessante, e alunos receptivos e motivados - elementos importantes no processo de ensino/aprendizagem. A elaboração de atividades práticas, principalmente aqueles que utilizam material alternativo ou de baixo custo, contribui como uma forma dinâmica de se ensinar Ciências.

Para a atividade prática, foram selecionados experimentos rápidos, com baixo custo, e de fácil manuseio, os quais foram utilizados na compreensão e fixação do conteúdo teórico (Tabela 2 e Figura 1). O tema, Enzimas, foi escolhido mediante um questionário pré-elaborado (Anexo $A$ ) que avaliou o conhecimento sobre Enzimas dos alunos participantes da pesquisa (Figuras 2A e 2B). 

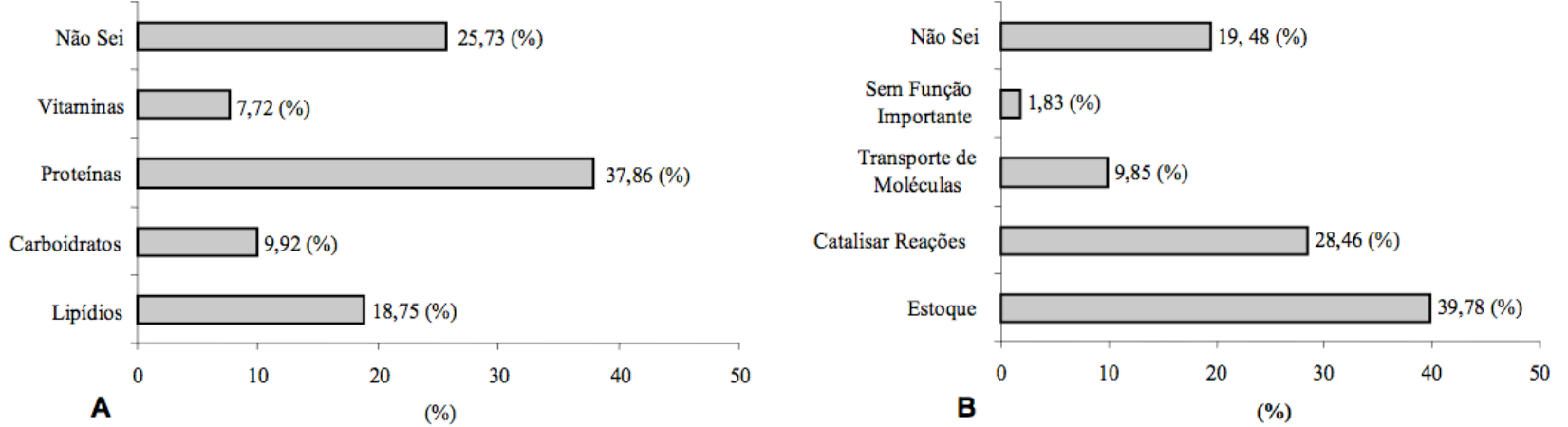

Figura 2: (A) Gráfico demonstrando o perfil da resposta dos alunos à pergunta: Sobre as enzimas é correto afirmar? (B) Gráfico demonstrando o perfil da resposta dos alunos à pergunta: As enzimas apresentam função?

Durante o ensino médio, os alunos discutem sobre a importância das Enzimas em vários temas estudados, tais como: Metabolismo e Respiração Celular, Fotossíntese, Digestão, Biologia Molecular etc. Porém, a frequente abordagem do tema não foi suficiente para consolidar os conceitos da natureza química e função das enzimas nos alunos que participaram deste trabalho (Tabela 1). Apenas 37,86\% destes alunos afirmaram que as enzimas são proteínas e $28,46 \%$ responderam que as enzimas catalisam reações (Figuras $2 \mathrm{~A}$ e $2 \mathrm{~B}$ ). Tais números deixam claro uma deficiência conceitual destes alunos perante os conceitos associados ao tema Enzimas, revelando a necessidade de uma nova metodologia de ensino para trabalhar tais conceitos.

Práticas experimentais que utilizam materiais alternativos e/ou de baixo custo financeiro ganham destaque no cenário das escolas públicas, devido à carência de recursos ideais para realização das mesmas. Neste trabalho, foi possível realizar uma prática com pouco recurso financeiro, sendo o liquidificador o único aparelho considerado dispendioso, porém esse eletrodoméstico foi encontrado nas cozinhas das escolas participantes deste estudo.

Transformar a sala de aula em um laboratório fica divertido e atrativo para os alunos, porém, o tempo de duração da prática é fundamental para consolidar a aprendizagem. É importante que as práticas sejam rápidas e que os alunos vejam as reações acontecerem, desta forma, despertando a capacidade investigativa destes estudantes. Práticas longas podem apresentar um efeito contrário ao esperado, ou seja, alunos impacientes e desconcentrados.

Alguns temas das Ciências Biológicas, ministrados durante o ensino médio, requerem uma capacidade de abstração dos alunos e, por esse motivo, às vezes, não são compreendidos. Neste estudo, trabalhamos o conceito de Atividade Enzimática utilizando uma atividade prática, desta forma mobilizando a curiosidade e capacidade criativa dos alunos.

O início da atividade prática foi precedido pela discussão de um texto base. Mesmo incentivados, poucos alunos participam da discussão. Tal fato pode estar associado à timidez dos alunos, ou inexperiência com esse tipo de atividade. Possivelmente, no decorrer de sua vida escolar esses alunos tiveram poucas oportunidades de expor suas opiniões e discutir conceitos com o professor.

Durante a prática, os alunos foram executores dos experimentos, cabendo aos professores apenas supervisão. O envolvimento dos alunos na realização dos experimentos foi notório, isto é, sentiram-se interessados e motivados, mostraram cuidado e habilidade em todas as etapas da prática. Posto isso, é importante destacar que aulas práticas possibilitam aos alunos/estudantes trabalhar em grupos, num sistema de cooperação entre eles, dando oportunidade a todos de expressar suas idéias, bem como despertando respeito mútuo. 
Práticas experimentais são boas ferramentas para trabalhar de forma interdisciplinar o ensino de ciências. Neste contexto, a atividade prática selecionada não se limita apenas à execução de um protocolo experimental ou ao uso de materiais alternativos, mas, igualmente, possibilita trabalhar vários conceitos através da interdisciplinaridade. A princípio, a interdisciplinaridade foi realizada com três disciplinas: Biologia, Matemática e Química. Porém, outras áreas do conhecimento podem ser co-relacionadas ao longo de uma atividade prática tais como, Física, Língua Portuguesa, História, Geografia etc.

$\mathrm{Na}$ atividade 1 (Anexo B) trabalhou-se com os alunos a construção e interpretação gráfica, sendo construído um gráfico em papel milimetrado. Neste gráfico, os alunos esboçaram a velocidade da reação enzimática. Ao término da construção gráfica, os alunos foram incentivados a discutirem os conceitos de cinética enzimática (Anexo $\mathrm{C}$ ). Desta forma, foi possível trabalhar com os alunos conceitos de Matemática e Biologia. Para trabalhar os conceitos de Biologia e Química, foi proposta uma atividade em que os alunos verificavam a interferência do $\mathrm{pH}$ no processo reacional. Neste ponto foi possível reafirmar os conceitos de $\mathrm{pH}$ ácido, básico e neutro.

Outro aspecto discutido com os alunos foram os erros experimentais. Ficou claro para os alunos que a metodologia aplicada nesta prática pode induzir erros experimentais, pois os instrumentos utilizados não são precisos e/ou calibrados.

Durante a execução dos experimentos, os alunos anotaram os procedimentos adotados e observações feitas, sendo que tais anotações foram utilizadas para uma posterior discussão, seguindo o roteiro do anexo D. Nesta discussão, os alunos participaram efetivamente, ao contrário da discussão do texto base. Tal fato está associado à construção do conhecimento de forma coletiva, estimulando os participantes a exporem suas opiniões e teorias formuladas.

Em função do grande interesse destes alunos, foi solicitada a elaboração de relatórios, em grupos, para serem lidos na sala de aula; desta forma provocando um intercâmbio com toda turma.

Ao término da prática, os alunos foram consultados a respeito da mesma. O fato de a maioria aprovar a atividade prática (Tabela 3) abre espaço para uma mudança na concepção de ensino puramente teórico para aquele com uma abordagem experimental. Posto isso, o presente estudo elucida e corrobora a possibilidade de unir o ensino tradicional e atividades práticas, mesmo sem laboratório e/ou equipamentos. Neste sentido, ainda, os materiais alternativos comuns, utilizados no dia a dia dos estudantes, mostraram que as rações Bioquímicas fazem parte de seu cotidiano.

Essas informações permitem afirmar que, mesmo diante do ensino tradicional e da falta de recursos e curto período de tempo das aulas, é possível realizar atividades práticas como um instrumento didático.

Tabela 3: Perfil da resposta dos alunos à pergunta: Em sua opinião a atividade prática foi?

\begin{tabular}{l|l}
\hline Resposta & N (\%) \\
\hline Ruim & $1(0,36)$ \\
\hline Regular & $11(4,01)$ \\
\hline Boa & $58(21,17)$ \\
\hline Muito Boa & $202(73,72)$ \\
\hline
\end{tabular}

Tabela 4: Perfil da resposta dos alunos à pergunta: Em sua opinião o uso de materiais alternativos na realização da prática foi satisfatório?

\begin{tabular}{l|l}
\hline Resposta & N (\%) \\
\hline Sim & $268(97,81)$ \\
\hline Não & $4(2,19)$ \\
\hline
\end{tabular}

Ao realizar uma atividade experimental a segurança é um critério essencial, pois estas não podem colocar em risco a integridade física dos alunos. Neste sentido, adotar a metodologia de materiais alternativos é uma boa solução, pois reagentes tóxicos e agressivos ao organismo (Peróxido de Hidrogênio e Ácido Acético) são 
substituídos por materiais comercializados em farmácias e supermercados (Água oxigenada 10 vol. e Vinagre). Além disso, os utensílios que no laboratório, normalmente, são de vidros podem ser substituídos por material plástico, desta forma, evitando possíveis acidentes com vidraria quebrada.

Outro ponto importante, na realização de uma atividade prática, é o descarte de resíduos. Sempre que possível, ao escolher uma atividade prática, o professor deve evitar sua produção. As práticas alternativas, em sua maioria, por utilizaram materiais de uso cotidiano, não produzem resíduos tóxicos ou poluentes. Sendo assim, o professor não encontrará problemas para descartar esse material.

Ao final da prática, fica claro que o conceito de enzima e a função desempenhada por essas moléculas (Tabelas 5 e 6 ) foram compreendidos pela maioria dos alunos.

Tabela 5: Perfil da resposta dos alunos à pergunta: Em sua opinião a atividade prática esclareceu a definição de enzimas?

\begin{tabular}{l|l}
\hline definição de enzimas? \\
\hline Resposta & N (\%) \\
\hline Sim & $265(96,71)$ \\
\hline Não & $7(3,29)$ \\
\hline
\end{tabular}

Tabela 6: Perfil da resposta dos alunos à pergunta: Em sua opinião atividade prática esclareceu a função das enzimas para os seres vivos?

\begin{tabular}{l|l}
\hline Resposta & N (\%) \\
\hline Sim & $264(96,35)$ \\
\hline Não & $8(3,65)$ \\
\hline
\end{tabular}

Portanto, atividades experimentais elaboradas com materiais alternativos e/ou de baixo custo podem, quando inseridas no ambiente escolar, contribuir na consolidação do processo de ensino/aprendizagem.

\section{CONCLUSÃO}

É inegável a importância das aulas expositivas no processo de ensino/aprendizagem, porém a predominância desta metodologia deixa as aulas cansativas e pouco atrativas. Neste contexto, a mudança na metodologia de um ensino puramente teórico para uma metodologia que favoreça a participação ativa dos alunos pode contribuir em envolvimento e entusiasmo, aguçando a criatividade e interesse, bem como tornando o aprendizado dinâmico e atrativo aos alunos.

As práticas propostas neste trabalho apresentam: execução simples e rápida, fácil manuseio, baixo custo, interdisciplinaridade, e, sobremaneira, são adaptáveis às condições das escolas. Além disso, não necessitam de um laboratório e podem ser realizadas na própria sala de aula.

A maioria dos alunos que participaou deste trabalho aprovou a metodologia de ensino e afirma que a atividade esclareceu suas dúvidas conceituais.

Por conseguinte, no contexto deste estudo, fica notório que a capacidade criativa do professor é a principal ferramenta para implementar novas estratégias didáticas utilizando materiais alternativas e/ou de baixo custo.

\section{REFERÊNCIAS BIBLIOGRÁFICAS}

[1] Krasilchik, M. (1987). O Professor e o Currículo das Ciências. São Paulo: EPU/EDUSP.

[2] Krasilchik, M. (2004). Prática de ensino de Biologia. 4a Ed. São Paulo: EPU/EDUSP. 
[3] Moreira, M. L \& Diniz, R. E. S. (2003). O laboratório de Biologia no Ensino Médio: infra-estrutura e outros aspectos relevantes. In: Universidade Estadual Paulista - PróReitoria de Graduação. (Org.). Núcleos de Ensino. São Paulo: Editora da UNESP.

[4] Brasil. (1999). Parâmetros Curriculares Nacionais: Ensino Médio: ciências da natureza, matemática e suas tecnologias. Brasília: MEC/Secretaria de Educação Média e Tecnológica.

[5] Moreira, L. M. (2007). O uso do corpo como ferramenta pedagógica: um modelo alternativo que desconsidera a ausência de recursos específicos para o ensino de bioquímica e biologia molecular no ensino fundamental. Revista Brasileira de Ensino de bioquímica e biologia molecular, v.1, p.1-14.

[6] Amabis, J. M., Martho, G. R. (2001). Fundamentos de biologia moderna. Editora Moderna, São Paulo.

[7] Luz, M. R. M. P. da (2004). Instrumentação ao Ensino de Bioquímica e Biologia Celular. Rio de Janeiro, Fundação CECIERJ. v.1.

[8] Chrispino, A. (1989). Ensinando Química Experimental Com Metodologia Alternativo. Química Nova. V.12, No 2.

[9] Gonçalves, A. P \& Marques, C. A. (2006). Contribuições pedagógicas e espistemológicas em experimentação no ensino de química. Investigações em Ensino de Ciências, v.11(2), p. 219-238.

[10] Borges, A. T. (2002). Novos rumos para o laboratório escolar de ciências. Caderno Brasileiro de Ensino de Física, v.19, n. 3, p.291-313. 